\title{
A Review of Machine Vision-Based Structural Health Monitoring: Methodologies and Applications
}

\author{
X. W. Ye, C. Z. Dong, and T. Liu \\ Department of Civil Engineering, Zhejiang University, Hangzhou 310058, China \\ Correspondence should be addressed to X. W. Ye; cexwye@zju.edu.cn
}

Received 21 March 2016; Revised 20 September 2016; Accepted 17 October 2016

Academic Editor: Calogero M. Oddo

Copyright ( 2016 X. W. Ye et al. This is an open access article distributed under the Creative Commons Attribution License, which permits unrestricted use, distribution, and reproduction in any medium, provided the original work is properly cited.

\begin{abstract}
In the past two decades, a significant number of innovative sensing and monitoring systems based on the machine vision-based technology have been exploited in the field of structural health monitoring (SHM). This technology has some inherent distinctive advantages such as noncontact, nondestructive, long distance, high precision, immunity to electromagnetic interference, and large-range and multiple-target monitoring. A lot of machine vision-based structural dynamic measurement and structural state inspection methods have been proposed. Real-world applications are also carried out to measure the structural physical parameters such as the displacement, strain/stress, rotation, vibration, crack, and spalling. The purpose of this review article is devoted to presenting a summary of the basic theories and practical applications of the machine vision-based technology employed in structural monitoring as well as its systematic error sources and integration with other modern sensing techniques.
\end{abstract}

\section{Introduction}

The technology of structural health monitoring (SHM) emerged with an essential goal of safeguarding the operational safety of engineering structures, through deploying various types of sensors, monitoring diversified physical quantities, assessing structural condition and performance, and instructing routine inspection and maintenance [1-6]. With regard to a large-scale SHM system, the innovative sensing technologies from a variety of fields, such as mechanics, electricity, electromagnetism, optics, thermology, and chemistry, make great contribution in accurately acquiring the huge amount of original data reflecting the real environmental and structural conditions. In the past three decades, worldwide researchers have devoted a considerable number of efforts in the development of novel sensing technologies for application in the SHM research field and achieved tremendous progresses.

With the great advances in optics device and computer science, the machine vision-based sensing and monitoring technology has been a cutting-edge research field and increasingly gained attentions from the civil engineering communities [7-12]. It is mainly due to its unique advantages of noncontact, long distance, high precision, immunity to electromagnetic interference in multipoint, and large-range structural measurement/monitoring [13-17]. Up to now, many vision-based analysis methods have been developed for structural displacement measurement, strain/stress monitoring, vibration response monitoring, crack or defection inspection, and characterization, among others [18-23].

In the past years, review works referring to the machine vision-based structural monitoring and condition assessment were carried out by some researchers. Wu and Casciati [24] gave a brief introduction of the vision-based positioning system for structural monitoring. Jiang et al. [25] reviewed the development and application of close-range photogrammetry in deformation and geometry measurement of bridges. Koch et al. [26] presented a comprehensive synthesis of the state of the art in the concrete and asphalt structure defect detection and condition assessment based on the computer vision technology. However, an all-round summary of the visionbased structural monitoring and condition assessment is still desirable. This paper aims to provide a comprehensive review of machine vision-based monitoring of civil engineering infrastructure focusing on the relevant methodologies and practical applications. 


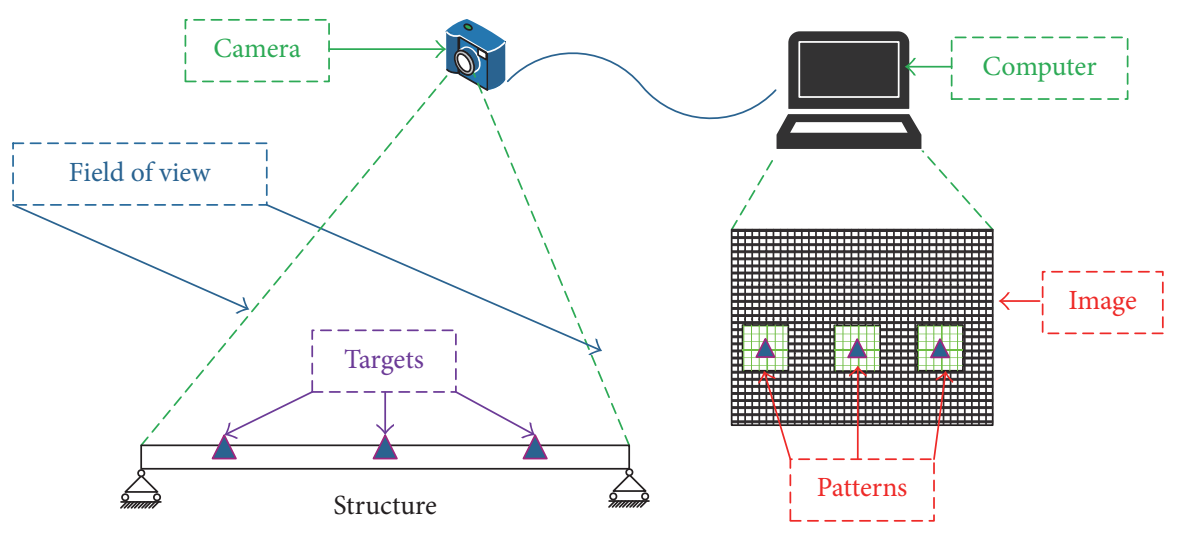

FIgURE 1: Two-dimensional vision-based displacement measurement method.

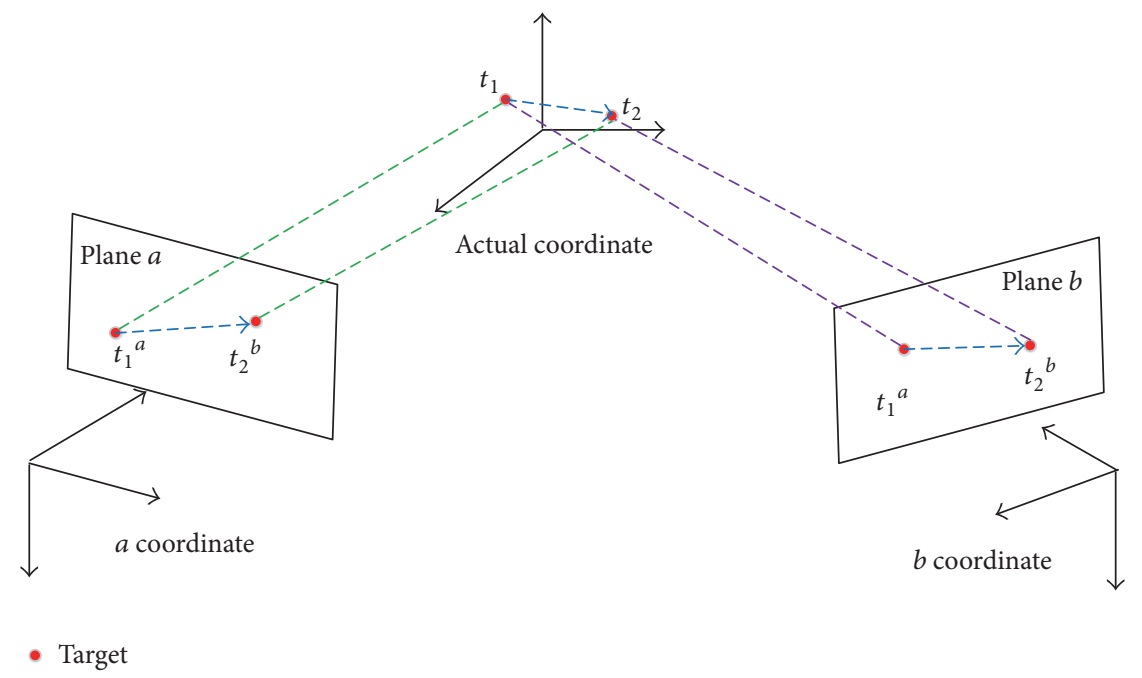

FIGURE 2: Three-dimensional vision-based displacement measurement method [35].

\section{Machine Vision Methods}

A vision-based measurement system generally consists of the image acquisition device (digital camera, lens, and image grabber), the computer, and an image processing software platform. In these mentioned components, the image processing software platform acts as the critical part which will be integrated with the specific computational algorithms to obtain the mechanical parameters in structural monitoring.

2.1. Image Processing Algorithms. As illustrated in Figure 1, the images including the predefined targets are captured by the digital camera. With the digital image processing and pattern matching algorithm [27-30], the targets are tracked and the structural displacements at the target positions on the structure can be obtained. In this occasion, the horizontal and vertical displacements, called two-dimensional (2D) displacements, can be obtained with one digital camera by use of the appropriate image processing method, such as digital image correlation [31], mean-shift tracking algorithm [32], CamShift tracking algorithm [33], and Lucas-Kanade method [34].
As illustrated in Figure 2, when two cameras are used to capture the targets simultaneously and the geometrical relationship between the two cameras (camera $a$ and camera $b$ ) is confirmed, the displacements of the targets in three coordinate directions, called three-dimensional (3D) displacements, can be derived by reconstructing the actual spatial displacements with the position changes on the two confirmed camera coordinates (the coordinates of Plane $a$ and Plane $b$ ) and the relationship between the two cameras [35].

For the image processing algorithms applied in structural monitoring, a considerable amount of research has been carried out over the last decades. Wang et al. [36] presented a method to get the displacement results from the interferometric images by use of the phase-shifted image matching algorithm. Pieraccini et al. [37] obtained the structural displacement of real-scale buildings from the images captured by a microwave interferometer. Guo and Zhu [34] proposed a modified inverse compositional algorithm to reduce the computing time of the Lucas-Kanade template tracking algorithm and improved the efficiency of computer vision method further in the remote measurement of dynamic displacement. Fukuda et al. [38] developed a robust object search algorithm 
enabling accurate displacement measurement through tracking existing features on the structure.

Busca et al. [39] used two types of cameras to acquire multiple targets fixed on a railway bridge during the passage of a train and obtained the displacement responses by three vision methods, that is, digital image correlation method, edge detection method, and pattern matching method. Lee et al. [40] proposed a pose-graph optimized displacement estimation method for reducing the estimation errors of a visually served paired structured light system. Nayyerloo et al. [41] developed a vision system to monitor the seismic response of structures with a line scan camera. Chan et al. [42] proposed a CCD camera-based method to measure the vertical displacement of bridges. Santos et al. [43] performed the vision system calibration in structural displacement measurement of long-deck suspension bridges.

\subsection{Systematic Errors Assessment and Reduction. Different} kinds of errors will occur in the application of visionbased measurement system. It is critical to find the influence factors, assess the systematic errors, and develop appropriate algorithms to reduce the errors. Lava et al. [44, 45] estimated the errors of system in the digital image correlation procedure for large plastic deformation monitoring and investigated the influence of different causes, including the subset shape function interpolation order, adopted correlation coefficient, and subset size. Schreier et al. [31, 46] analyzed the errors caused by the use of undermatched shape function and grayvalue interpolation in structural displacement measurement. Bornert et al. [47] studied the displacement errors assessment from synthetic speckle images and identified various error regimes. Yoneyama et al. [48] evaluated the effects of lens distortion on the displacement measurement and proposed a correction method when using the digital image correlation. Yu and Pan [49] investigated the errors due to the overmatched subset shape function via the numerical tests with deformation and the images from real experiments with high strain gradients. Baldi and Bertolino [50] conducted an experimental study to describe the errors caused by interpolation options. Zhou et al. [51] presented a method about the adaptive image subset offset to decrease the system errors in the incremental image correlation. Crammond et al. [52] investigated the relationship among the size and density of speckles and the measurement error within a pattern and identified that the physical properties had a significant impact on the precision of the displacement measurement. Yaofeng and Pang [53] investigated the effect of subset size on the accuracy of deformation measurement when using a digital image correlation algorithm. Lava et al. [54] estimated the errors produced when the camera alignment was nonperpendicular to planar sheet metal specimen's surface in a numerical experiment. Lecompte et al. [55] stated that the size of the speckle and the used pixel subset notably affected the error magnitude of the displacement measurement.

Santos et al. [56] proposed a vision system calibration approach to obtain an initial estimation of the object shape and camera parameters to reduce measurement errors. Ribeiro et al. [57] presented a video-based system for the dynamic displacement measurement of railway bridges and investigated several influence factors which will affect the measurement precision of the video-based system. Ma et al. [58] studied the error of strain measurement in digital image correlation method caused by self-heating of digital cameras. Haddadi and Belhabib [59] investigated the strain measurement errors due to digital image correlation technique with rigid-body motion. Fazzini et al. [60] estimated the errors due to digital image correlation in displacement measurement based on the generation of composite image models of genuine speckle patterns. Wu et al. [61] mounted a vision system to monitor the $2 \mathrm{D}$ plane dynamic response of a reduced scale frame fixed on a shaking table and discussed the physical meanings of the camera parameters, the balance between the system resolution and its field-of-view, and the upper limitation of maker density which would restrict the systematic error and measurement resolution.

The risk of the measurement uncertainty in the application of vision-based techniques to vibrating target measurements is very likely increased due to the motion blur generated by the camera-target motion. The motion blur will lead to significant systematic errors and incomplete measurement data because the target seeking process may not give exact detection. In recent years, research efforts have been devoted to the development of deblurring and denoising algorithms and blur image analysis methods [62-64]. Wang et al. [65] proposed a method for vibration measurement based on the blurred images with the aid of the relationship between the geometric moments of the unblurred and blurred motion. Peng et al. [66] developed an image restoration method for the improvement of the quality of dynamic particle images for the purpose of solving the motion-blurred problem in an online particle imaging system for wear debris analysis. Becker [67] conducted a study of motion blur evaluation by use of different basic approaches and instruments with a variety of parameter variations. Wu et al. [68] presented a row by row degradation model of the images and developed a restoration approach to compensate the space-variant degradation. Ishida et al. [69] proposed a method to improve the recognition accuracy of camera-captured characters without restoring images.

\section{Applications of Machine Vision Technology}

3.1. Two-Dimensional (2D) Structural Displacement Monitoring. With the image sequence, pattern matching algorithm, edge detection algorithm, and other image processing technologies, the structural displacement of predefined targets can be obtained. This can be used to obtain the dynamic displacement of several selected points on a certain structure for the purpose of structural monitoring. Feng et al. [70] proposed a vision system for noncontact structural displacement measurement in real time with the aid of an advanced template matching algorithm. Henke et al. [71] measured the deformation of building structures by use of digital image processing technique regarding the LED as the vision target. Park et al. [72] proposed a displacement measurement method based on machine vision technology to monitor the displacement of high-rise building structures by use of the partitioning approach and the verification experiments were 
conducted on a flexible steel column. Jáuregui et al. [73] employed the close-range terrestrial digital photogrammetry to measure the vertical deflection of bridges. Yoneyama et al. [74] used the digital image correlation to monitor the deflection of a new-built steel girder bridge during load tests. Kohut et al. [75] validated the feasibility and precision of a vision method for the measurement of steel bridge displacement. Dworakowski et al. [76] used the bridge deflection curve obtained by the in-plane displacement measurement based on the vision method to analyze the damage of the cantilever beam structures.

Lee et al. [77] employed the digital image processing techniques to obtain the real-time displacement of bridges and assess the bridge load carrying capacity. Ho et al. [78] developed a synchronous vision system for the real-time multipoint displacement measurement of civil infrastructure. Yang et al. [79] proposed an image-based method to measure the structural displacement, plane strain field, and cracks on the surface of the specimens under seismic loads. Fu and Moosa [80] proposed an optical method for displacement measurement with a high-resolution CCD camera. Olaszek [81] presented a computer vision method for realtime measuring the structural displacement and dynamic characteristics of bridges. Lee and Shinozuka [82] proposed a vision-based system to measure the dynamic displacement of bridges in real time with the aid of digital image processing techniques. Wahbeh et al. [83] developed a vision-based method to measure the absolute displacements in real time at selected locations of infrastructure.

The great advantage of the vision-based structural displacement measurement method is that the measurement targets can be multiple as soon as they are in the captured images. Choi et al. [84] introduced a dynamic displacement vision system which could perform the multimeasurement positions using a handset digital camcorder and the region of interest (ROI) was proposed to improve the measurement efficiency. Jurjo et al. [85] measured the large displacement at several points of the membrane simultaneously and estimated the strain and stress from the measured displacement. Lin et al. [86] presented a videogrammetry system to monitor the dynamic behavior of membrane roof structures. Lee and Shinozuka [87] developed a real-time vision-based system for structural displacement measurement of bridges by use of digital image processing techniques.

\subsection{Three-Dimensional (3D) Structural Displacement Mon-} itoring. As mentioned in Section 3.1, the 2D (or in-plane) structural displacement can be obtained with the image sequence captured by only one camera. Combined with two or more digital cameras, two different image sequences from two shooting angles are captured, and the three-dimensional (in-plane and out-plane) structural displacement of selected points on a certain structures can be realized with vision reconstruction techniques. Grano and Zinno [88] designed a computer vision system for displacement monitoring during destructive tests. Park et al. [35] presented an approach to monitor the three-dimensional structural displacements with the aid of a high speed motion-capture system which has the advantages of high accuracy and high sampling rate. Jeon et al. [89] proposed a vision system with an artificial marker to monitor six-degree-of-freedom (6-DOF) structural displacements. Park et al. [90] used a motion-capture system to obtain the 3D displacement response of structures in wind tunnel experiments and obtained the dynamic properties of the test structure, including the natural frequency, mode shape, and damping ratio. Jeon et al. [91] developed vision system to measure the 6-DOF structural displacement based on the paired visual servoing method. Leifer et al. [92] performed three-dimensional acceleration measurement by a videogrammetry system through tracking the motion of targets on a modal shaker. Synnergren and Sjödahl [93] developed a photography system with stereoscopic digital speckles for 3D displacement field measurements and a camera calibration algorithm was used to evaluate the effect of lens distortion. Viéville and Lingrand [94] developed a visual motion perception module to estimate $3 \mathrm{D}$ displacements without calibration.

$\mathrm{Hu}$ et al. [95] proposed a 4-camera video system for 3D motion measurement of deformable objects. Ji and Chang [96] presented a marker-free stereovision method to monitor responses of the line-like structures in both spatial and temporal domains. Chang and Ji [97] proposed a videogrammetric method based on the principle of digital photogrammetry in close-range and computer vision technology to measure the $3 \mathrm{D}$ structural vibration response in lab and proposed a two-step calibration process to overcome the lens distortion problem. Lee et al. [98] developed a vision-based displacement measurement system with digital image processing techniques for real-time structural health monitoring of civil structures. Chang and Xiao [99] presented a single-camera approach for simultaneously measuring the $3 \mathrm{D}$ motion (including the translation and rotation) of a target attached on civil structures. Greenbaum et al. [100] developed a vision method to measure rigid-body motion including (translation and rotation) experimental displacement in three-dimension rocking motion.

3.3. Structural Strain and Stress Monitoring. The vision-based methods were applied to acquire the structural strain and stress by use of the structural displacement obtained by the vision system and the relationship between the structural displacement and the strain and stress derived in the field of material mechanics. Carmo et al. [101] developed a method for assessment of steel strains on reinforced concrete members using solely surface measurement (crack width and spacing) with the aid of photogrammetry and image processing. Patterson et al. [102] described a material for the purpose of reference and calibration of the optical system for strain monitoring and designed a standardized test material. Winkler et al. [103] employed the digital image correlation method to measure the local deformations in steel monostrands. De Pauw et al. [104] used digital image correlation method to monitor the fatigue parameters of the coupon scale fretting tests. Gales et al. [105] introduced a digital image correlation method to measure the deformation and strain of the prestressing steel during high-temperature tests. Wang and Cuitio [106] applied the digital image correlation technique to capture the deformation patterns of polymeric foams. 
McGinnis et al. [107] applied the 3D digital image correlation method for determination of in situ stresses of concrete structures. Obaidat and Attom [108] used two CCD cameras to obtain the strain in soil specimens of two soil tests. Maekawa et al. [109] proposed a noncontact measurement method based on the optical displacement sensors using LEDs to measure the vibration stress and used the acquired stress to evaluate the vibration fatigue failure of small-bore piping systems. Carroll et al. [110] used the digital image correlation method to measure the strain of structures during the fatigue crack initiation and growth and evaluate the condition of cracks. Moilanen et al. [111] proposed an imagebased method to monitor the planar strain and stress distribution in heterogeneous and soft materials.

3.4. Vibration Monitoring and Dynamic Characteristics Identification. The structural displacement can be acquired with a high speed camera at a high sample rate which can satisfy the need of structural vibration monitoring and dynamic characteristics identification such as the natural frequency, modal damping ratio, and modal shape. Chen et al. [112] proposed a digital photogrammetry method for measurement of the ambient vibration response and identification of the mode shape ratio of stay cables with multiple camcorders. Oh et al. [113] presented a vision-based system for estimation of the dynamic characteristics of the structure by using displacement time histories for a motion-capture system. Jurjo et al. [114] proposed a structural displacement measurement method based on digital image processing techniques to conduct the dynamic analysis of slender structures. Fukuda et al. [115] developed a vision-based system to monitor the dynamic response of large-scale civil infrastructure which was more cost-effective.

Kim [116] proposed a multitemplate matching algorithm to obtain the modal parameters of a cable from blurred motion images. Park et al. [90] applied a motion-capture system to monitor the 3D displacement response of a structure in wind tunnel experiments and to identify the dynamic properties of the test structure. Caetano et al. [117] developed a vision-based system to monitor the vibration of slender structures. Jeon et al. [118] presented a method to conduct modal tests using a camera image which could measure the vibration of many points at the same time. Chung et al. [119] applied image processing technique to acquire nonlinear characteristic parameters of mechanical and structural systems. Ji and Chang [120] presented a nontarget imagebased method to measure small cable dynamic responses using an optical flow method. Kohut and Kurowski [121] developed a vision-based method to realize the 3D measurement of structural vibration displacements and modal characteristics by use of operational modal analysis algorithms.

The vibration-based structural damage detection methods have obtained great advances in the area of structural health monitoring. The vision-based dynamic monitoring methods can be applied in the procedure of the vibrationbased structural damage detection to give a stable signal input. Poudel et al. [122] obtained the structural dynamic displacement time series using high-resolution subpixel edge identification based image processing method and developed the mode shape difference function to detect structural damage. Patsias and Staszewski [123] developed a new damage detection method with the aid of wavelets and modal shape data which was measured optically. Li et al. [124] developed a digital image processing method to measure the rivulet vibration of an inclined cable in wind tunnel tests and evaluate the rivulet vibration characteristics.

3.5. Crack Inspection and Characterization. With the aid of advanced image processing technology, the structural surface features can be analyzed from the images such as cracks and spalling on the steel and concrete structures. Yeum and Dyke [125] proposed a vision-based visual inspection technique through the automatic process and analysis of a large number of captured images for detection of the cracks near bolts on the bridges. Liu et al. [126] proposed a method for automated surface crack monitoring and assessment of concrete structures based on adaptive digital image processing. Halfawy and Hengmeechai [127] embedded the visionbased defection recognition system into the closed circuit television (CCTV) system mounted in the sewer to inspect its defections automatically. Adhikari et al. [128] presented an approach of automated condition assessment of concrete bridges based on digital image analyses.

German et al. [129] developed a column damage index for quantitative assessment of the visible damage (cracks and spalling) on the RC structural members enhanced by machine vision techniques to realize rapid building inspection after earthquake. Ho et al. [130] developed an imagebased system with three cameras attached to a cable climbing robot to detect surface damage of cables using image processing and pattern recognition techniques. Valença et al. [131] presented a visual method which recognized the concrete health monitoring automatically including measuring the displacement and stain, detecting damages, identifying cracks, and restoration.

Gul et al. [132] proposed an image-based monitoring method for the detection of open gears of movable bridges in lubrication level to assess the condition and make maintenance decision. Sakagami [133] presented a remote nondestructive evaluation technique using infrared thermography to detect fatigue cracks and assess the structural integrity. Liu et al. [134] combined the two-dimensional image processing technology and three-dimensional reconstruction method to assess the crack characteristics of concrete structures automatically to solve the hindrance in the practical implementation of traditional two-dimensional method. Wu et al. [135] developed a crack defragmentation technique based on image processing techniques to improve the crack-detection accuracy in the road assessment task.

3.6. Integration Technology. Through integrating with other sensing approaches, the machine vision technology was broadened to be used in more specific application categories. Vaghefi et al. [136] developed a combined nondestructive imaging technology on a bridge deck to yield both surface and subsurface indicators of condition. Stabile et al. [137] 
used a suite of microwave radar interferometer and a thermal camera to monitor dynamic displacement of bridges. Catbas et al. [138] carried out the bridge load rating with the aid of traditional sensors and traffic video data. Zaurin and Catbas [139] integrated the video images and sensor data from structural monitoring system to evaluate the safety condition of bridges. Luo et al. [140] developed a vision inspection system combining machine vision, laser interferometer, and coordinate measuring machine. Waldbjørn et al. [141] obtained the feedback signals (strain and displacement) by the fiber Bragg grating and digital image correlation when conducting the test control. Mazzoleni and Zappa [142] presented a vision-based method to estimate the vertical dynamic loading caused by human motions on structures. Hack and Leroy [143] used the cameras orthogonally aligned to monitor the mandrel position by measuring the rigid-body displacement based on a multivariate least-squares algorithm. Integrated with the monocular laser triangle measuring method, Gao et al. [144] used the image processing method to get the $3 \mathrm{D}$ displacement of superconducting tokamak magnets.

\section{Conclusions}

This paper provides a review of the research and progress in the area of structural monitoring of civil infrastructure by use of the machine vision-based technology. Based on a comprehensive review of the machine vision-based methods, technologies, applications, and systematic error assessment, the following concluding remarks are made: (i) due to their unique merits for structural monitoring, the machine visionbased technology has been widely used to measure the 2D and 3D structural displacement, strain/stress, dynamic response, crack, and spalling, (ii) the machine vision technology can be applied to conduct the structural dynamic parameter identification and damage diagnosis in combination with the existing vibration-based analysis methods, and (iii) the vision-based methods are potential to provide more valuable information for the visual inspection and structural monitoring through integrating with other sensing techniques.

Although the great advances and achievements on the vision-based SHM have been made, some critical limitations and challenges of the developed techniques are still existent; for example, (i) most of the current research is conducted through the laboratory tests with scale physical models, and the research outcomes may not be realized in the field continuous monitoring because of the complicated site conditions, (ii) the quality of the images captured by the vision device will be significantly affected by the surrounding environment conditions, such as the light variation, edge shelter by rain, snow and fog, ground vibration, and (iii) as an interdisciplinary and cutting-edge technology, a big challenge is still encountered from the establishment of a scientific and effective cooperative mechanism between the researchers from civil engineering and optoelectronic engineering.

\section{Competing Interests}

The authors declare that they have no competing interests.

\section{Acknowledgments}

The work described in this paper was jointly supported by the National Science Foundation of China (Grant no. 51308493) and the Research Fund for the Doctoral Program of Higher Education of China (Grant no. 20130101120080).

\section{References}

[1] Y. Q. Ni, X. W. Ye, and J. M. Ko, "Monitoring-based fatigue reliability assessment of steel bridges: analytical model and application," Journal of Structural Engineering, vol. 136, no. 12, pp. 1563-1573, 2010.

[2] Y. Q. Ni, X. W. Ye, and J. M. Ko, "Modeling of stress spectrum using long-term monitoring data and finite mixture distributions," Journal of Engineering Mechanics, vol. 138, no. 2, pp. 175183,2012

[3] X. W. Ye, Y. H. Su, P. S. Xi, B. Chen, and J. P. Han, "Statistical analysis and probabilistic modeling of WIM monitoring data of an instrumented arch bridge," Smart Structures and Systems, vol. 17, no. 6, pp. 1087-1105, 2016.

[4] X. W. Ye, Y. H. Su, and J. P. Han, "Structural health monitoring of civil infrastructure using optical fiber sensing technology: a comprehensive review," The Scientific World Journal, vol. 2014, Article ID 652329, 11 pages, 2014.

[5] X. W. Ye, Y. Q. Ni, and J. H. Yin, "Safety monitoring of railway tunnel construction using FBG sensing technology," Advances in Structural Engineering, vol. 16, no. 8, pp. 1401-1409, 2013.

[6] X. W. Ye, Y. Q. Ni, K. Y. Wong, and J. M. Ko, "Statistical analysis of stress spectra for fatigue life assessment of steel bridges with structural health monitoring data," Engineering Structures, vol. 45, pp. 166-176, 2012.

[7] C. S. Fraser, "Some thoughts on the emergence of digital close range photogrammetry," Photogrammetric Record, vol. 16, no. 91, pp. 37-50, 1998.

[8] C.-W. Lin, W.-K. Hsu, D.-J. Chiou, C.-W. Chen, and W.-L. Chiang, "Smart monitoring system with multi-criteria decision using a feature based computer vision technique," Smart Structures and Systems, vol. 15, no. 6, pp. 1583-1600, 2015.

[9] N. Gonçalves, V. Carvalho, M. Belsley, R. M. Vasconcelos, F. O. Soares, and J. Machado, "Yarn features extraction using image processing and computer vision-a study with cotton and polyester yarns," Measurement, vol. 68, pp. 1-15, 2015.

[10] R. Shanmugamani, M. Sadique, and B. Ramamoorthy, "Detection and classification of surface defects of gun barrels using computer vision and machine learning," Measurement, vol. 60, pp. 222-230, 2015.

[11] T. Schmidt, J. Tyson, and K. Galanulis, "Full-field dynamic displacement and strain measurement using advanced 3D image correlation photogrammetry: part I," Experimental Techniques, vol. 27, no. 3, pp. 47-50, 2003.

[12] D. C. Zhu, Y. P. Feng, Q. Chen, and J. B. Cai, "Image recognition technology in rotating machinery fault diagnosis based on artificial immune," Smart Structures and Systems, vol. 6, no. 4, pp. 389-403, 2010.

[13] J.-H. Lee, H.-N. Ho, M. Shinozuka, and J.-J. Lee, "An advanced vision-based system for real-time displacement measurement of high-rise buildings," Smart Materials and Structures, vol. 21, no. 12, Article ID 125019, pp. 1-10, 2012.

[14] J.-J. Lee, H.-N. Ho, and J.-H. Lee, "A vision-based dynamic rotational angle measurement system for large civil structures," Sensors, vol. 12, no. 6, pp. 7326-7336, 2012. 
[15] D. Y. Lee, H. Tippur, M. Kirugulige, and P. Bogert, "Experimental study of dynamic crack growth in unidirectional graphite/ epoxy composites using digital image correlation method and high-speed photography," Journal of Composite Materials, vol. 43, no. 19, pp. 2081-2108, 2009.

[16] M. R. Jahanshahi, S. F. Masri, and G. S. Sukhatme, "Multiimage stitching and scene reconstruction for evaluating defect evolution in structures," Structural Health Monitoring, vol. 10, no. 6, pp. 643-657, 2011.

[17] C. Koch, S. Paal, A. Rashidi, Z. Zhu, M. König, and I. Brilakis, "Achievements and challenges in machine vision-based inspection of large concrete structures," Advances in Structural Engineering, vol. 17, no. 3, pp. 303-318, 2014.

[18] C. Cheng and K. Kawaguchi, "A preliminary study on the response of steel structures using surveillance camera image with vision-based method during the Great East Japan Earthquake," Measurement, vol. 62, pp. 142-148, 2015.

[19] T. C. Hutchinson and F. Kuester, "Monitoring global earthquake-induced demands using vision-based sensors," IEEE Transactions on Instrumentation and Measurement, vol. 53, no. 1, pp. 31-36, 2004.

[20] Y. C. Tsai, J. P. Wu, Z. H. Wang, and Z. Z. Hu, "Horizontal roadway curvature computation algorithm using vision technology," Computer-Aided Civil and Infrastructure Engineering, vol. 25, no. 2, pp. 78-88, 2010.

[21] N. G. Woodhouse, S. Robson, and J. R. Eyre, "Vision metrology and three dimensional visualization in structural testing and monitoring," Photogrammetric Record, vol. 16, no. 94, pp. 625641, 1999.

[22] H. Fathi and I. Brilakis, "Multistep explicit stereo camera calibration approach to improve euclidean accuracy of large-scale $3 \mathrm{D}$ reconstruction," Journal of Computing in Civil Engineering, vol. 30, no. 1, Article ID 04014120, 2016.

[23] J.-H. Park, T.-C. Huynh, S.-H. Choi, and J.-T. Kim, "Visionbased technique for bolt-loosening detection in wind turbine tower," Wind and Structures, vol. 21, no. 6, pp. 709-726, 2015.

[24] L. J. Wu and F. Casciati, "Local positioning systems versus structural monitoring: a review," Structural Control and Health Monitoring, vol. 21, no. 9, pp. 1209-1221, 2014.

[25] R. N. Jiang, D. V. Jáuregui, and K. R. White, "Close-range photogrammetry applications in bridge measurement: literature review," Measurement, vol. 41, no. 8, pp. 823-834, 2008.

[26] C. Koch, K. Georgieva, V. Kasireddy, B. Akinci, and P. Fieguth, "A review on computer vision based defect detection and condition assessment of concrete and asphalt civil infrastructure," Advanced Engineering Informatics, vol. 29, no. 2, pp. 196-210, 2015.

[27] X. W. Ye, Y. Q. Ni, T. T. Wai, K. Y. Wong, X. M. Zhang, and F. $\mathrm{Xu}$, "A vision-based system for dynamic displacement measurement of long-span bridges: algorithm and verification," Smart Structures and Systems, vol. 12, no. 3-4, pp. 363-379, 2013.

[28] X. W. Ye, T.-H. Yi, C. Z. Dong, T. Liu, and H. Bai, "Multipoint displacement monitoring of bridges using a vision-based approach," Wind and Structures, vol. 20, no. 2, pp. 315-326, 2015.

[29] X. W. Ye, C. Z. Dong, and T. Liu, "Force monitoring of steel cables using vision-based sensing technology: methodology and experimental verification," Smart Structures and Systems, vol. 18, no. 3, pp. 585-599, 2016.

[30] X. W. Ye, T. H. Yi, C. Z. Dong, and T. Liu, "Vision-based structural displacement measurement: system performance evaluation and influence factor analysis," Measurement, vol. 88, pp. 372-384, 2016.
[31] H. W. Schreier and M. A. Sutton, "Systematic errors in digital image correlation due to undermatched subset shape functions," Experimental Mechanics, vol. 42, no. 3, pp. 303-310, 2002.

[32] X. W. Ye, C. Z. Dong, and T. Liu, "Image-based structural dynamic displacement measurement using different multiobject tracking algorithms," Smart Structures and Systems, vol. 17, no. 6, pp. 935-956, 2016.

[33] S.-H. Yen, C.-H. Wang, and J.-C. Chien, "Accurate and robust ROI localization in a camshift tracking application," Multimedia Tools and Applications, vol. 74, no. 23, pp. 10291-10312, 2015.

[34] J. Guo and C. Zhu, "Dynamic displacement measurement of large-scale structures based on the Lucas-Kanade template tracking algorithm," Mechanical Systems and Signal Processing, vol. 66-67, pp. 425-436, 2016.

[35] S. W. Park, H. S. Park, J. H. Kim, and H. Adeli, “3D displacement measurement model for health monitoring of structures using a motion capture system," Measurement, vol. 59, pp. 352-362, 2015.

[36] Z. B. Wang, M. S. Graça, P. J. Bryanston-Cross, and D. J. Whitehouse, "Phase-shifted image matching algorithm for displacement measurement," Optical Engineering, vol. 35, no. 8, pp. 2327-2332, 1996.

[37] M. Pieraccini, G. Luzi, D. Mecatti et al., "Remote sensing of building structural displacements using a microwave interferometer with imaging capability," NDT and E International, vol. 37, no. 7, pp. 545-550, 2004.

[38] Y. Fukuda, M. Q. Feng, Y. Narita, S. Kaneko, and T. Tanaka, "Vision-based displacement sensor for monitoring dynamic response using robust object search algorithm," IEEE Sensors Journal, vol. 13, no. 12, pp. 4725-4732, 2013.

[39] G. Busca, A. Cigada, P. Mazzoleni, and E. Zappa, "Vibration monitoring of multiple bridge points by means of a unique vision-based measuring system," Experimental Mechanics, vol. 54, no. 2, pp. 255-271, 2014.

[40] D. H. Lee, H. M. Jeon, and H. Myung, "Pose-graph optimized displacement estimation for structural displacement monitoring," Smart Structures and Systems, vol. 14, no. 5, pp. 943-960, 2014.

[41] M. Nayyerloo, J. G. Chase, A. Millane et al., "Seismic structural displacement measurement using a line-scan camera: camerapattern calibration and experimental validation," Journal of Civil Structural Health Monitoring, vol. 1, no. 3-4, pp. 113-124, 2011.

[42] T. H. T. Chan, D. B. Ashebo, H. Y. Tam et al., "Vertical displacement measurements for bridges using optical fiber sensors and CCD cameras-A Preliminary Study," Structural Health Monitoring, vol. 8, no. 3, pp. 243-249, 2009.

[43] C. A. Santos, C. O. Costa, and J. P. Batista, "Calibration methodology of a vision system for measuring the displacements of long-deck suspension bridges," Structural Control and Health Monitoring, vol. 19, no. 3, pp. 385-404, 2012.

[44] P. Lava, S. Cooreman, S. Coppieters, M. De Strycker, and D. Debruyne, "Assessment of measuring errors in DIC using deformation fields generated by plastic FEA," Optics and Lasers in Engineering, vol. 47, no. 7-8, pp. 747-753, 2009.

[45] P. Lava, S. Cooreman, and D. Debruyne, "Study of systematic errors in strain fields obtained via DIC using heterogeneous deformation generated by plastic FEA," Optics and Lasers in Engineering, vol. 48, no. 4, pp. 457-468, 2010.

[46] H. W. Schreier, J. R. Braasch, and M. A. Sutton, "Systematic errors in digital image correlation caused by intensity interpolation," Optical Engineering, vol. 39, no. 11, pp. 2915-2921, 2000. 
[47] M. Bornert, F. Brémand, P. Doumalin et al., "Assessment of digital image correlation measurement errors: methodology and results," Experimental Mechanics, vol. 49, no. 3, pp. 353-370, 2009.

[48] S. Yoneyama, H. Kikuta, A. Kitagawa, and K. Kitamura, "Lens distortion correction for digital image correlation by measuring rigid body displacement," Optical Engineering, vol. 45, no. 2, Article ID 023602, 2006.

[49] L. P. Yu and B. Pan, "The errors in digital image correlation due to overmatched shape functions," Measurement Science and Technology, vol. 26, no. 4, Article ID 045202, pp. 1-9, 2015.

[50] A. Baldi and F. Bertolino, "Experimental analysis of the errors due to polynomial interpolation in digital image correlation," Strain, vol. 51, no. 3, pp. 248-263, 2015.

[51] Y. H. Zhou, C. Sun, and J. B. Chen, "Adaptive subset offset for systematic error reduction in incremental digital image correlation," Optics and Lasers in Engineering, vol. 55, pp. 5-11, 2014.

[52] G. Crammond, S. W. Boyd, and J. M. Dulieu-Barton, "Speckle pattern quality assessment for digital image correlation," Optics and Lasers in Engineering, vol. 51, no. 12, pp. 1368-1378, 2013.

[53] S. Yaofeng and J. H. L. Pang, "Study of optimal subset size in digital image correlation of speckle pattern images," Optics and Lasers in Engineering, vol. 45, no. 9, pp. 967-974, 2007.

[54] P. Lava, S. Coppieters, Y. Wang, P. Van Houtte, and D. Debruyne, "Error estimation in measuring strain fields with DIC on planar sheet metal specimens with a non-perpendicular camera alignment," Optics and Lasers in Engineering, vol. 49, no. 1, pp. 57-65, 2011.

[55] D. Lecompte, A. Smits, S. Bossuyt et al., "Quality assessment of speckle patterns for digital image correlation," Optics and Lasers in Engineering, vol. 44, no. 11, pp. 1132-1145, 2006.

[56] C. A. Santos, C. O. Costa, and J. P. Batista, "Long deck suspension bridge monitoring: the vision system calibration problem," Strain, vol. 48, no. 2, pp. 108-123, 2012.

[57] D. Ribeiro, R. Calçada, J. Ferreira, and T. Martins, "Non-contact measurement of the dynamic displacement of railway bridges using an advanced video-based system," Engineering Structures, vol. 75, pp. 164-180, 2014.

[58] S. P. Ma, J. Z. Pang, and Q. W. Ma, "The systematic error in digital image correlation induced by self-heating of a digital camera," Measurement Science and Technology, vol. 23, no. 2, Article ID 025403, pp. 1-7, 2012.

[59] H. Haddadi and S. Belhabib, "Use of rigid-body motion for the investigation and estimation of the measurement errors related to digital image correlation technique," Optics and Lasers in Engineering, vol. 46, no. 2, pp. 185-196, 2008.

[60] M. Fazzini, S. Mistou, O. Dalverny, and L. Robert, "Study of image characteristics on digital image correlation error assessment," Optics and Lasers in Engineering, vol. 48, no. 3, pp. 335339, 2010.

[61] L.-J. Wu, F. Casciati, and S. Casciati, "Dynamic testing of a laboratory model via vision-based sensing," Engineering Structures, vol. 60, pp. 113-125, 2014.

[62] V. Caglioti and A. Giusti, "Recovering ball motion from a single motion-blurred image," Computer Vision and Image Understanding, vol. 113, no. 5, pp. 590-597, 2009.

[63] M. D. Kim and J. Ueda, "Dynamics-based motion de-blurring for a PZT-driven, compliant camera orientation mechanism," International Journal of Robotics Research, vol. 34, no. 4-5, pp. 653-673, 2015.
[64] Y. Zhang and K. Hirakawa, "Blind deblurring and denoising of images corrupted by unidirectional object motion blur and sensor noise," IEEE Transactions on Image Processing, vol. 25, no. 9, pp. 4129-4144, 2016.

[65] S. Wang, B. Guan, G. Wang, and Q. Li, "Measurement of sinusoidal vibration from motion blurred images," Pattern Recognition Letters, vol. 28, no. 9, pp. 1029-1040, 2007.

[66] Y. Peng, T. Wu, S. Wang, N. Kwok, and Z. Peng, "Motionblurred particle image restoration for on-line wear monitoring," Sensors, vol. 15, no. 4, pp. 8173-8191, 2015.

[67] M. E. Becker, "Motion-blur evaluation: a comparison of approaches," Journal of the Society for Information Display, vol. 16, no. 10, pp. 989-1000, 2008.

[68] J. G. Wu, Z. Z. Zheng, H. J. Feng, Z. H. Xu, Q. Li, and Y. T. Chen, "Restoration of TDI camera images with motion distortion and blur," Optics and Laser Technology, vol. 42, no. 8, pp. 1198-1203, 2010.

[69] H. Ishida, T. Takahashi, I. Ide, Y. Mekada, and H. Murase, "Recognition of camera-captured low-quality characters using motion blur information," Pattern Recognition, vol. 41, no. 7, pp. 2253-2262, 2008.

[70] D. Feng, M. Q. Feng, E. Ozer, and Y. Fukuda, "A vision-based sensor for noncontact structural displacement measurement," Sensors, vol. 15, no. 7, pp. 16557-16575, 2015.

[71] K. Henke, R. Pawlowski, P. Schregle, and S. Winter, "Use of digital image processing in the monitoring of deformations in building structures," Journal of Civil Structural Health Monitoring, vol. 5, no. 2, pp. 141-152, 2015.

[72] J.-W. Park, J.-J. Lee, H.-J. Jung, and H. Myung, "Vision-based displacement measurement method for high-rise building structures using partitioning approach," NDT and E International, vol. 43, no. 7, pp. 642-647, 2010.

[73] D. V. Jáuregui, K. R. White, C. B. Woodward, and K. R. Leitch, "Noncontact photogrammetric measurement of vertical bridge deflection," Journal of Bridge Engineering, vol. 8, no. 4, pp. 212222, 2003.

[74] S. Yoneyama, A. Kitagawa, S. Iwata, K. Tani, and H. Kikuta, "Bridge deflection measurement using digital image correlation,” Experimental Techniques, vol. 31, no. 1, pp. 34-40, 2007.

[75] P. Kohut, K. Holak, T. Uhl et al., "Monitoring of a civil structure's state based on noncontact measurements," Structural Health Monitoring, vol. 12, no. 5-6, pp. 411-429, 2013.

[76] Z. Dworakowski, P. Kohut, A. Gallina, K. Holak, and T. Uhl, "Vision-based algorithms for damage detection and localization in structural health monitoring," Structural Control and Health Monitoring, vol. 23, no. 1, pp. 35-50, 2016.

[77] J. J. Lee, S. J. Cho, M. Shinozuka, C. B. Yun, C. G. Lee, and W. T. Lee, "Evaluation of bridge load carrying capacity based on dynamic displacement measurement using real-time image processing techniques," International Journal of Steel Structures, vol. 6, no. 5, pp. 377-385, 2006.

[78] H.-N. Ho, J.-H. Lee, Y.-S. Park, and J.-J. Lee, "A synchronized multipoint vision-based system for displacement measurement of civil infrastructures," The Scientific World Journal, vol. 2012, Article ID 519146, 9 pages, 2012.

[79] Y.-S. Yang, C.-W. Huang, and C.-L. Wu, "A simple image-based strain measurement method for measuring the strain fields in an RC-wall experiment," Earthquake Engineering and Structural Dynamics, vol. 41, no. 1, pp. 1-17, 2012.

[80] G. K. Fu and A. G. Moosa, "An optical approach to structural displacement measurement and its application," Journal of Engineering Mechanics, vol. 128, no. 5, pp. 511-520, 2002. 
[81] P. Olaszek, "Investigation of the dynamic characteristic of bridge structures using a computer vision method," Measurement, vol. 25, no. 3, pp. 227-236, 1999.

[82] J. J. Lee and M. Shinozuka, "Real-time displacement measurement of a flexible bridge using digital image processing techniques," Experimental Mechanics, vol. 46, no. 1, pp. 105-114, 2006.

[83] A. M. Wahbeh, J. P. Caffrey, and S. F. Masri, "A vision-based approach for the direct measurement of displacements in vibrating systems," Smart Materials and Structures, vol. 12, no. 5, pp. 785-794, 2003.

[84] H.-S. Choi, J.-H. Cheung, S.-H. Kim, and J.-H. Ahn, "Structural dynamic displacement vision system using digital image processing," NDT and E International, vol. 44, no. 7, pp. 597-608, 2011.

[85] D. L. B. R. Jurjo, C. Magluta, N. Roitman, and P. B. Gonçalves, "Analysis of the structural behavior of a membrane using digital image processing," Mechanical Systems and Signal Processing, vol. 54, pp. 394-404, 2015.

[86] S.-Y. Lin, J. P. Mills, and P. D. Gosling, "Videogrammetric monitoring of as-built membrane roof structures," The Photogrammetric Record, vol. 23, no. 122, pp. 128-147, 2008.

[87] J. J. Lee and M. Shinozuka, "A vision-based system for remote sensing of bridge displacement," NDT and E International, vol. 39, no. 5, pp. 425-431, 2006.

[88] A. Grano and R. Zinno, "A new low-cost displacements monitoring system based on Kinect sensor," Journal of Civil Structural Health Monitoring, vol. 5, no. 5, pp. 727-733, 2015.

[89] H. Jeon, Y. Kim, D. Lee, and H. Myung, "Vision-based remote 6DOF structural displacement monitoring system using a unique marker," Smart Structures and Systems, vol. 13, no. 6, pp. 927942, 2014.

[90] H. S. Park, J. Y. Kim, J. G. Kim, S. W. Choi, and Y. Kim, "A new position measurement system using a motion-capture camera for wind tunnel tests," Sensors, vol. 13, no. 9, pp. 12329-12344, 2013.

[91] H. M. Jeon, Y. S. Bang, and H. Myung, "A paired visual servoing system for 6-DOF displacement measurement of structures," Smart Materials and Structures, vol. 20, no. 4, Article ID 045019, 2011.

[92] J. Leifer, B. J. Weems, S. C. Kienle, and A. M. Sims, “Threedimensional acceleration measurement using videogrammetry tracking data," Experimental Mechanics, vol. 51, no. 2, pp. 199217, 2011.

[93] P. Synnergren and M. Sjödahl, "A stereoscopic digital speckle photography system for 3-D displacement field measurements," Optics and Lasers in Engineering, vol. 31, no. 6, pp. 425-443, 1999.

[94] T. Viéville and D. Lingrand, "Using specific displacements to analyze motion without calibration," International Journal of Computer Vision, vol. 31, no. 1, pp. 5-29, 1999.

[95] H. Hu, J. Liang, Z.-Z. Xiao, Z.-Z. Tang, A. K. Asundi, and Y.-X. Wang, "A four-camera videogrammetric system for 3-D motion measurement of deformable object," Optics and Lasers in Engineering, vol. 50, no. 5, pp. 800-811, 2012.

[96] Y. F. Ji and C. C. Chang, "Nontarget stereo vision technique for spatiotemporal response measurement of line-like structures," Journal of Engineering Mechanics, vol. 134, no. 6, pp. 466-474, 2008.

[97] C. C. Chang and Y. F. Ji, "Flexible videogrammetric technique for three-dimensional structural vibration measurement," Journal of Engineering Mechanics, vol. 133, no. 6, pp. 656-664, 2007.
[98] J. J. Lee, Y. Fukuda, M. Shinozuka, S. Cho, and C.-B. Yun, "Development and application of a vision-based displacement measurement system for structural health monitoring of civil structures," Smart Structures and Systems, vol. 3, no. 3, pp. 373384, 2007.

[99] C. C. Chang and X. H. Xiao, “Three-dimensional structural translation and rotation measurement using monocular videogrammetry," Journal of Engineering Mechanics, vol. 136, no. 7, pp. 840-848, 2010.

[100] R. J. Y. Greenbaum, A. W. Smyth, and M. N. Chatzis, "Monocular computer vision method for the experimental study of threedimensional rocking motion," Journal of Engineering Mechanics, vol. 142, no. 1, Article ID 04015062, 2016.

[101] R. N. F. Carmo, J. Valença, D. Silva, and D. Dias-Da-Costa, "Assessing steel strains on reinforced concrete members from surface cracking patterns," Construction and Building Materials, vol. 98, pp. 265-275, 2015.

[102] E. A. Patterson, E. Hack, P. Brailly et al., "Calibration and evaluation of optical systems for full-field strain measurement," Optics and Lasers in Engineering, vol. 45, no. 5, pp. 550-564, 2007.

[103] J. Winkler, G. Fischer, and C. T. Georgakis, "Measurement of local deformations in steel monostrands using digital image correlation," Journal of Bridge Engineering, vol. 19, no. 10, Article ID 04014042, 2014.

[104] J. De Pauw, W. De Waele, R. Hojjati-Talemi, and P. De Baets, "On the use of digital image correlation for slip measurement during coupon scale fretting fatigue experiments," International Journal of Solids and Structures, vol. 51, no. 18, pp. 3058-3066, 2014.

[105] J. A. Gales, L. A. Bisby, and T. Stratford, "New parameters to describe high-temperature deformation of prestressing steel determined using digital image correlation," Structural Engineering International, vol. 22, no. 4, pp. 476-486, 2012.

[106] Y. Wang and A. M. Cuitio, "Full-field measurements of heterogeneous deformation patterns on polymeric foams using digital image correlation," International Journal of Solids and Structures, vol. 39, no. 13-14, pp. 3777-3796, 2002.

[107] M. J. McGinnis, S. Pessiki, and H. Turker, "Application of three-dimensional digital image correlation to the core-drilling method," Experimental Mechanics, vol. 45, no. 4, pp. 359-367, 2005.

[108] M. T. Obaidat and M. F. Attom, "Computer vision-based technique to measure displacement in selected soil tests," Geotechnical Testing Journal, vol. 21, no. 1, pp. 31-37, 1998.

[109] A. Maekawa, T. Takahashi, T. Tsuji, and M. Noda, "Experimental validation of non-contacting measurement method using LED-optical displacement sensors for vibration stress of smallbore piping," Measurement, vol. 71, pp. 1-10, 2015.

[110] J. D. Carroll, W. Abuzaid, J. Lambros, and H. Sehitoglu, "High resolution digital image correlation measurements of strain accumulation in fatigue crack growth," International Journal of Fatigue, vol. 57, pp. 140-150, 2013.

[111] C. S. Moilanen, P. Saarenrinne, B. A. Engberg, and T. Björkqvist, "Image-based stress and strain measurement of wood in the split-Hopkinson pressure bar," Measurement Science and Technology, vol. 26, no. 8, Article ID 085206, 2015.

[112] C.-C. Chen, W.-H. Wu, H.-Z. Tseng, C.-H. Chen, and G. Lai, "Application of digital photogrammetry techniques in identifying the mode shape ratios of stay cables with multiple camcorders," Measurement, vol. 75, pp. 134-146, 2015.

[113] B. K. Oh, J. W. Hwang, Y. S. Kim, T. J. Cho, and H. S. Park, "Vision-based system identification technique for building 
structures using a motion capture system," Journal of Sound and Vibration, vol. 356, pp. 72-85, 2015.

[114] D. L. B. R. Jurjo, C. Magluta, N. Roitman, and P. B. Gonçalves, "Experimental methodology for the dynamic analysis of slender structures based on digital image processing techniques," Mechanical Systems and Signal Processing, vol. 24, no. 5, pp. 1369-1382, 2010.

[115] Y. Fukuda, M. Q. Feng, and M. Shinozuka, "Cost-effective vision-based system for monitoring dynamic response of civil engineering structures," Structural Control and Health Monitoring, vol. 17, no. 8, pp. 918-936, 2010.

[116] B. H. Kim, "Extracting modal parameters of a cable on shaky motion pictures," Mechanical Systems and Signal Processing, vol. 49, no. 1-2, pp. 3-12, 2014.

[117] E. Caetano, S. Silva, and J. Bateira, "A vision system for vibration monitoring of civil engineering structures," Experimental Techniques, vol. 35, no. 4, pp. 74-82, 2011.

[118] H.-S. Jeon, Y.-C. Choi, J.-H. Park, and J. W. Park, "Multi-point measurement of structural vibration using pattern recognition from camera image," Nuclear Engineering and Technology, vol. 42, no. 6, pp. 704-711, 2010.

[119] H.-C. Chung, J. Liang, S. Kushiyama, and M. Shinozuka, "Digital image processing for non-linear system identification," International Journal of Non-Linear Mechanics, vol. 39, no. 5, pp. 691-707, 2004.

[120] Y. F. Ji and C. C. Chang, "Nontarget image-based technique for small cable vibration measurement," Journal of Bridge Engineering, vol. 13, no. 1, pp. 34-42, 2008.

[121] P. Kohut and P. Kurowski, "Application of modal analysis supported by $3 \mathrm{~d}$ vision-based measurements," Journal of Theoretical and Applied Mechanics, vol. 47, no. 4, pp. 855-870, 2009.

[122] U. P. Poudel, G. Fu, and J. Ye, "Structural damage detection using digital video imaging technique and wavelet transformation," Journal of Sound and Vibration, vol. 286, no. 4-5, pp. 869-895, 2005.

[123] S. Patsias and W. J. Staszewski, "Damage detection using optical measurements and wavelets," Structural Health Monitoring, vol. 1, no. 1, pp. 5-22, 2002.

[124] Y. L. Li, H. Q. Jing, Y. Xia, Y. L. Xu, and H. Y. Xiang, "Measurement of rivulet movement on inclined cables during rain-wind induced vibration," Sensors and Actuators A: Physical, vol. 230, pp. 17-24, 2015.

[125] C. M. Yeum and S. J. Dyke, "Vision-based automated crack detection for bridge inspection," Computer-Aided Civil and Infrastructure Engineering, vol. 30, no. 10, pp. 759-770, 2015.

[126] Y. F. Liu, S. J. Cho, B. F. Spencer, and J. S. Fan, "Automated assessment of cracks on concrete surfaces using adaptive digital image processing," Smart Structures and Systems, vol. 14, no. 4, pp. 719741, 2014.

[127] M. R. Halfawy and J. Hengmeechai, "Integrated vision-based system for automated defect detection in sewer closed circuit television inspection videos," Journal of Computing in Civil Engineering, vol. 29, no. 1, Article ID 04014024, 2015.

[128] R. S. Adhikari, A. Bagchi, and O. Moselhi, "Automated condition assessment of concrete bridges with digital imaging," Smart Structures and Systems, vol. 13, no. 6, pp. 901-925, 2014.

[129] S. German, J.-S. Jeon, Z. H. Zhu et al., "Machine visionenhanced postearthquake inspection," Journal of Computing in Civil Engineering, vol. 27, no. 6, pp. 622-634, 2013.

[130] H.-N. Ho, K.-D. Kim, Y.-S. Park, and J.-J. Lee, "An efficient image-based damage detection for cable surface in cable-stayed bridges," NDT and E International, vol. 58, pp. 18-23, 2013.
[131] J. Valença, D. Dias-da-Costa, L. Gonçalves, E. Júlio, and H. Araújo, "Automatic concrete health monitoring: assessment and monitoring of concrete surfaces," Structure and Infrastructure Engineering, vol. 10, no. 12, pp. 1547-1554, 2014.

[132] M. Gul, F. N. Catbas, and H. Hattori, "Image-based monitoring of open gears of movable bridges for condition assessment and maintenance decision making," Journal of Computing in Civil Engineering, vol. 29, no. 2, Article ID 04014034, 2015.

[133] T. Sakagami, "Remote nondestructive evaluation technique using infrared thermography for fatigue cracks in steel bridges," Fatigue \& Fracture of Engineering Materials \& Structures, vol. 38, no. 7, pp. 755-779, 2015.

[134] Y.-F. Liu, S. Cho, B. F. Spencer, and J.-S. Fan, "Concrete crack assessment using digital image processing and 3D scene reconstruction," Journal of Computing in Civil Engineering, vol. 30, no. 1, Article ID 04014124, 2016.

[135] L. L. Wu, S. Mokhtari, A. Nazef, B. Nam, and H.-B. Yun, "Improvement of crack-detection accuracy using a novel crack defragmentation technique in image-based road assessment," Journal of Computing in Civil Engineering, vol. 30, no. 1, Article ID 04014118, pp. 1-19, 2016.

[136] K. Vaghefi, T. M. Ahlborn, D. K. Harris, and C. N. Brooks, "Combined imaging technologies for concrete bridge deck condition assessment," Journal of Performance of Constructed Facilities, vol. 29, no. 4, Article ID 04014102, 2015.

[137] T. A. Stabile, A. Giocoli, A. Perrone, A. Palombo, S. Pascucci, and S. Pignatti, "A new joint application of non-invasive remote sensing techniques for structural health monitoring," Journal of Geophysics and Engineering, vol. 9, no. 4, pp. S53-S63, 2012.

[138] F. N. Catbas, R. Zaurin, M. Gul, and H. B. Gokce, "Sensor networks, computer imaging, and unit influence lines for structural health monitoring: case study for bridge load rating," Journal of Bridge Engineering, vol. 17, no. 4, pp. 662-670, 2012.

[139] R. Zaurin and F. N. Catbas, "Integration of computer imaging and sensor data for structural health monitoring of bridges," Smart Materials and Structures, vol. 19, no. 1, Article ID 015019, 2010.

[140] P. F. Luo, S. P. Pan, and T. C. Chu, "Application of computer vision and laser interferometer to the inspection of line scale," Optics and Lasers in Engineering, vol. 42, no. 5, pp. 563-584, 2004.

[141] J. Waldbjørn, J. Høgh, J. Wittrup-Schmidt et al., "Strain and displacement controls by fibre bragg grating and digital image correlation," Strain, vol. 50, no. 3, pp. 262-273, 2014.

[142] P. Mazzoleni and E. Zappa, "Vision-based estimation of vertical dynamic loading induced by jumping and bobbing crowds on civil structures," Mechanical Systems and Signal Processing, vol. 33, pp. 1-12, 2012.

[143] E. Hack and D. Leroy, "Camera-based monitoring of the rigidbody displacement of a mandrel in superconducting cable production," Optics and Lasers in Engineering, vol. 43, no. 3-5, pp. 455-474, 2005.

[144] Q. Gao, W. Xi, Y. Song, Y. Li, Y. Chen, and L. Lei, "Study on three-dimensional displacement measurement method of EAST cold magnet based on computer vision," Journal of Fusion Energy, vol. 33, no. 5, pp. 489-496, 2014. 


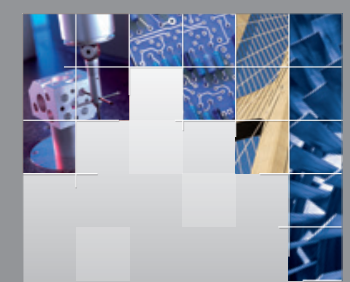

\section{Enfincering}
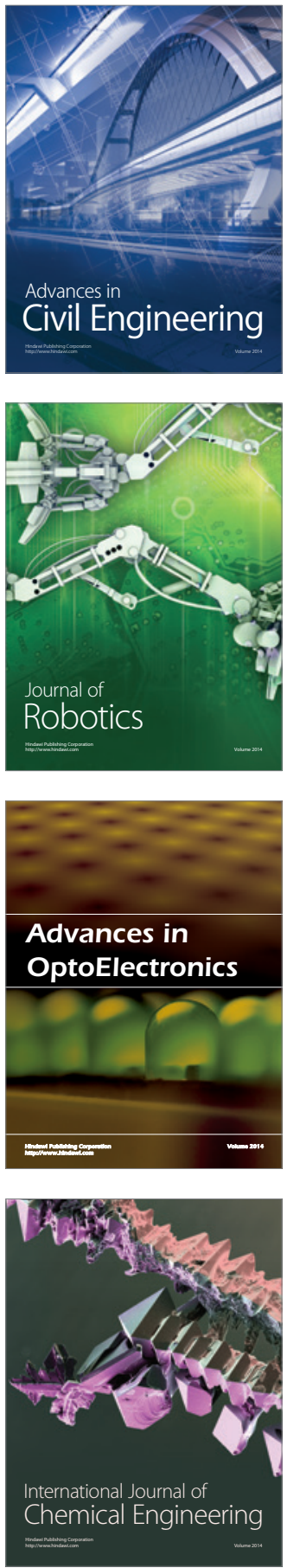

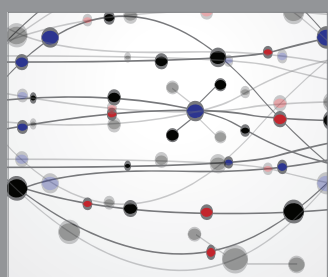

The Scientific World Journal

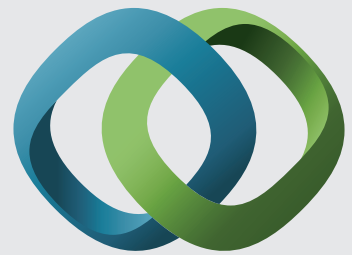

\section{Hindawi}

Submit your manuscripts at

http://www.hindawi.com
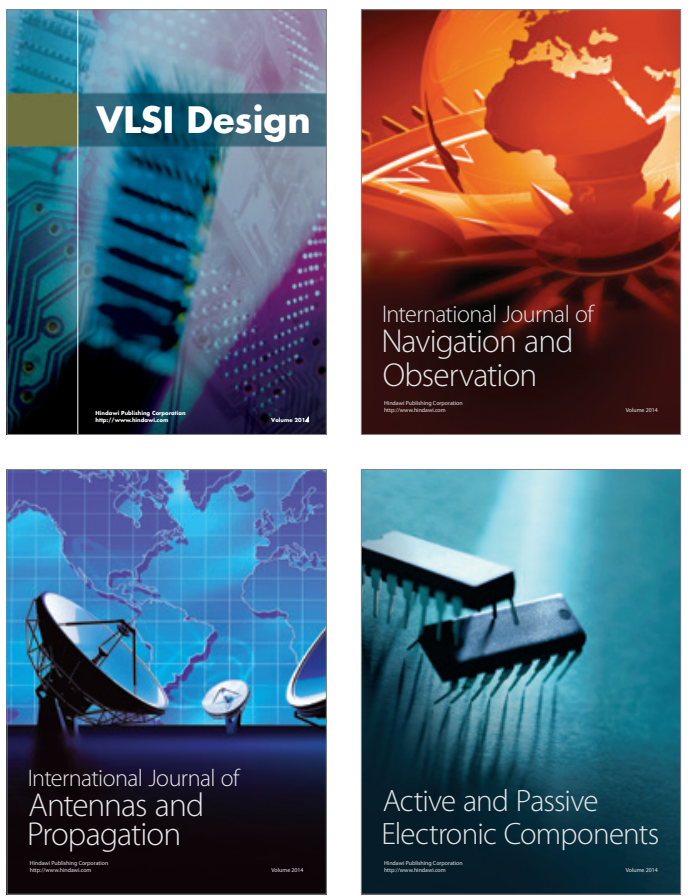
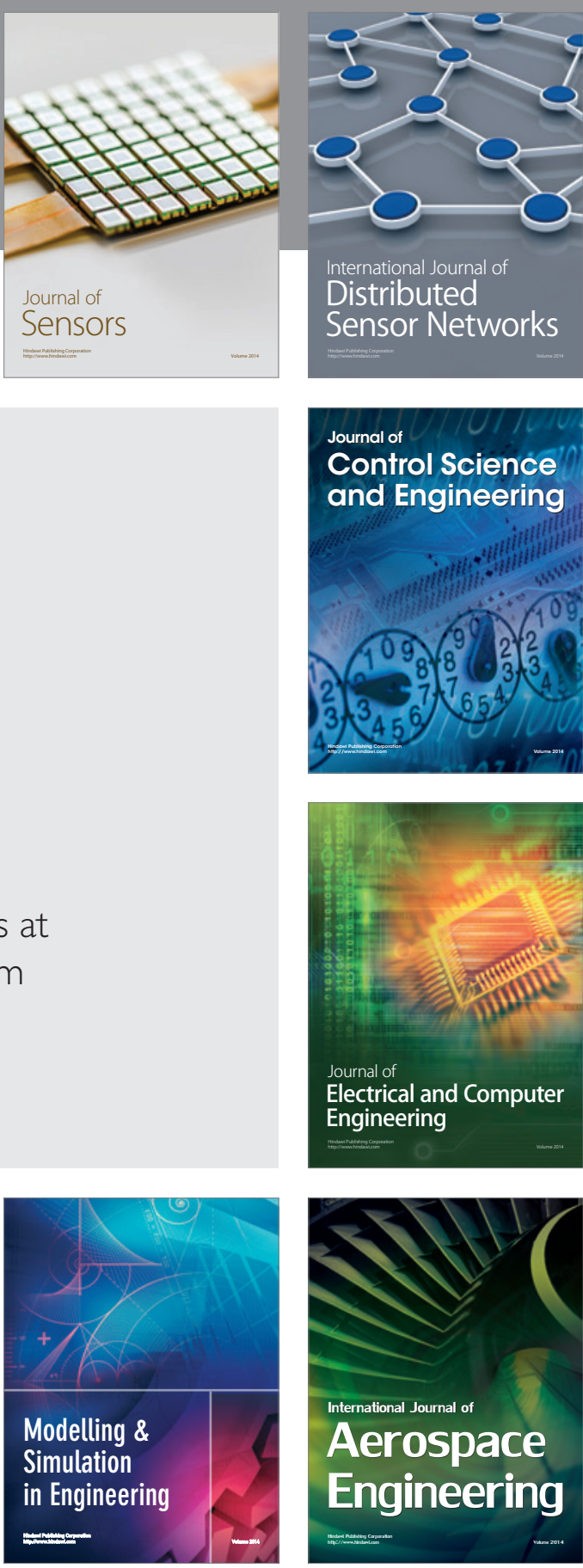

International Journal of

Distributed

Sensor Networks

Journal of

Control Science

and Engineering
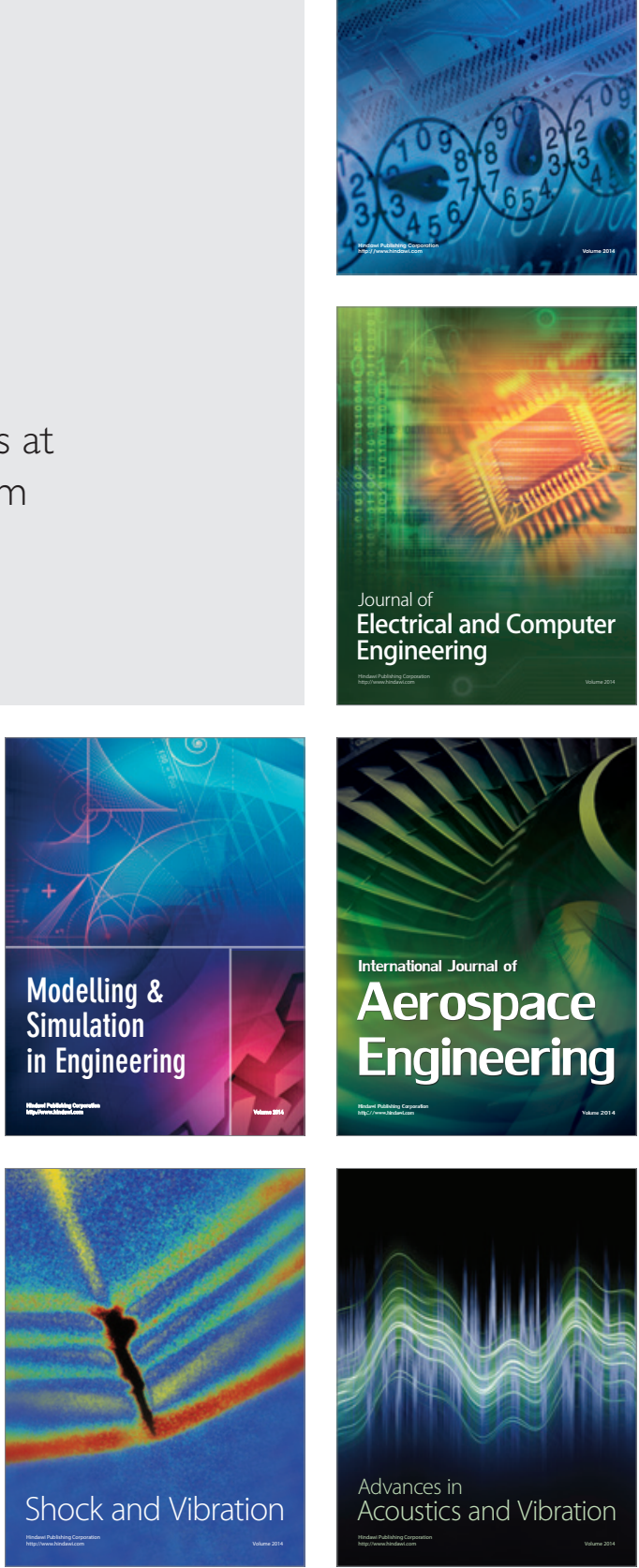